ARTICLE

https://doi.org/10.1038/s41467-019-10674-3

\title{
Synergetic iridium and amine catalysis enables asymmetric [4+2] cycloadditions of vinyl aminoalcohols with carbonyls
}

\author{
Mao-Mao Zhang ${ }^{1}$, Ya-Ni Wang ${ }^{1}$, Bao-Cheng Wang ${ }^{1}$, Xiao-Wang Chen ${ }^{1}$, Liang-Qiu Lu,2 \& Wen-Jing Xiao ${ }^{1,3}$
}

Catalytic asymmetric cycloadditions via transition-metal-containing dipolar intermediates are a powerful tool for synthesizing chiral heterocycles. However, within the field of palladium catalysis, compared with the well-developed normal electron-demand cycloadditions with electrophilic dipolarophiles, a general strategy for inverse electron-demand ones with nucleophilic dipolarophiles remains elusive, due to the inherent linear selectivity in the key palladium-catalyzed intermolecular allylations. Herein, based on the switched regioselectivity of iridium-catalyzed allylations, we achieved two asymmetric [4+2] cycloadditions of vinyl aminoalcohols with aldehydes and $\beta, \gamma$-unsaturated ketones through synergetic iridium and amine catalysis. The activation of vinyl aminoalcohols by iridium catalysts and carbonyls by amine catalysts provide a foundation for the subsequent asymmetric [4+2] cycloadditions of the resulting iridium-containing 1,4-dipoles and (di)enamine dipolarophiles. The former provides a straightforward route to a diverse set of enantio-enriched hydroquinolines bearing chiral quaternary stereocenters, and the later represent an enantio- and diastereodivergent synthesis of chiral hydroquinolines.

\footnotetext{
${ }^{1}$ CCNU-uOttawa Joint Research Centre, Key Laboratory of Pesticide and Chemical Biology, Ministry of Education; College of Chemistry, Central China Normal University, 152 Luoyu Road, Wuhan 430079, China. ${ }^{2}$ State Key Laboratory for Oxo Synthesis and Selective Oxidation, Lanzhou Institute of Chemical Physics (LICP), Chinese Academy of Sciences, Lanzhou 730000, China. ${ }^{3}$ State Key Laboratory of Applied Organic Chemistry, College of Chemistry and Chemical Engineering, Lanzhou University, Lanzhou 730000, China. Correspondence and requests for materials should be addressed to L.-Q.

L. (email: luliangqiu@mail.ccnu.edu.cn) or to W.-J.X. (email: wxiao@mail.ccnu.edu.cn)
} 
eterocycles are privileged motifs in fields ranging from pharmaceutical chemistry and agrochemistry to materials chemistry and life sciences. The development of efficient synthetic methods for preparing heterocyclic compounds has been a major focus of the synthetic community ${ }^{1,2}$. Among the continuing and productive efforts, catalytic asymmetric cycloadditions via transition metal (TM)-containing dipolar intermediates have been determined to be powerful tools for this purpose $^{3-5}$. Within this realm of palladium catalysis, although many impressive advancements have been made regarding cycloadditions of Pd-containing dipolar intermediates with electrophilic dipolarophiles (Fig. 1a, path a: normal electron-demand cycloadditions $)^{6-12}$, the inherent linear selectivity of Pd-catalyzed intermolecular allylic alkylation (AA) reactions renders the development of a general strategy for the coupling of such intermediates with nucleophilic dipolarophiles a formidable task (Fig. 1a, path b: inverse electron-demand cycloaddition) ${ }^{13,14}$. In the few known examples, some additional interaction (i.e., electrostatic interactions or hydrogen bonding interactions) between the Pd-containing dipole and nucleophilic dipolarophile was required to induce branched selectivity in the Pd-catalyzed intermolecular AA processes ${ }^{15-19}$. For this reason, the exploitation of alternative catalyst systems is required to develop general dipolar cycloadditions and efficiently utilize the synthetic potential of TM catalysis in the synthesis of heterocycles.

Based on the pioneering works of Takeuchi ${ }^{20,21}$ and Helmchen $^{22}$, as well as the substantial contribution from Helmchen ${ }^{23}$, Hartwig $^{24}$, Carreira ${ }^{25}$, You ${ }^{26}$ and many other excellent scientists $^{27-29}$, iridium-catalyzed AA reactions show excellent branched selectivity, which distinguishes them from Pd-catalyzed processes ${ }^{30}$. Recent studies have indicated that iridium catalysis is compatible with many other catalysis modes (i.e., phase catalysis $^{31}$, amine catalysis ${ }^{32-34}$, Lewis base catalysis ${ }^{35}$, Brønsted acid catalysis $^{36}$, and Lewis acid catalysis ${ }^{37-40}$ ), significantly expanding the scope of Ir-catalyzed asymmetric allylic alkylation (AAA) reactions ${ }^{41}$. Inspired by these impressive achievements, we question whether a synergetic catalysis strategy involving iridium catalysis can be adopted to resolve the remaining problem associated with Pd-catalyzed inverse electron-demand cycloadditions. More interestingly, readily available vinyl aminoalcohols can be directly utilized as coupling partners in TM-catalyzed cycloadditions using Ir-containing dipoles (Fig. 1b), avoiding the use of vinyl-substituted strained rings and carbonates like those required in Pd-catalyzed cycloaddition (Fig. 1a). Here, through the combination of iridium and amine catalysis, we accomplished the [4+2] cycloadditions of vinyl aminoalcohols with

aldehydes and $\beta, \gamma$-unsaturated ketones. Optically active quinolinones and tetrahydroquinolines were produced in good yields and with high diastereoselectivity and enantioselectivity.

\section{Results}

Design plan. Hydroquinolines are a class of important azaheterocycles that are ubiquitous in natural alkaloids and functional molecules (i.e., pharmaceuticals, agrochemicals, and chiral ligands $)^{42-44}$. Among existing methods for synthesizing chiral hydroquinolines, catalytic asymmetric $[4+2]$ cycloadditions stand out as one of the most streamlined approaches ${ }^{45-49}$. As part of our ongoing studies on the synthesis of heterocycles via TMcatalyzed cycloadditions ${ }^{15,50-55}$, in this work, we plan to develop reaction methodologies that utilize readily available reagents and feature good selectivity and high synthetic efficiency. A detailed description of a possible mechanism is outlined in Fig. 2. We envision that two catalytic cycles could act in concert to realize this cycloaddition via the following steps: (1) the Ir catalyst reacts with vinyl aminoalcohol 1a to form Ir-containing dipole int. $\mathbf{I}^{56,57}$; (2) the amine catalyst condenses with the aldehyde to generate enamine species II; (3) these two transient species, I and II, react with each other to produce int. III, which can be further converted to hemiacetal 4 through an intramolecular cyclization $($ III $\rightarrow$ IV) and acid-promoted hydrolysis process $(\mathbf{I V} \rightarrow \mathbf{4})$. Based on this mechanism, a diverse set of hydroquinolines can be generated in a facile manner by in situ conversion of the $\mathrm{OH}$ group to a variety of other functional groups $(4 \rightarrow 3 / 5)$. While attractive in theory, the construction of contiguous stereocenters and chiral all-carbon quaternary stereocenters ${ }^{58-62}$, as well as the compatibility between the catalysts, substrates, and additives are challenges that must be addressed.

Condition optimization. First, we investigated the Ir/aminecatalyzed cycloaddition/oxidation sequence using vinyl aminoalcohol 1a and aldehyde 2a. The use of $4 \mathrm{~mol} \%$ of chiral $\mathrm{Ir}$

a Pd-catalyzed dipolar cycloadditions: well developed

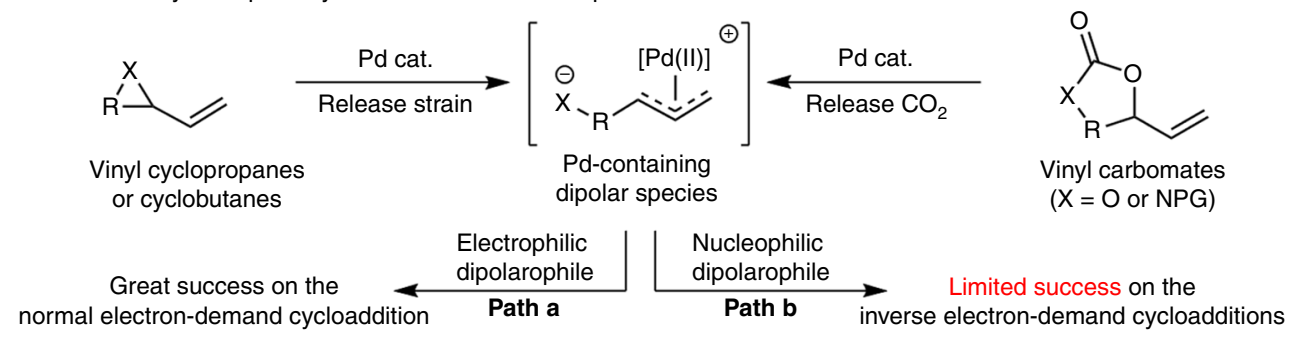

Cause: favored or difavored branched selectivity in intramolecular or intermolecular AA steps, respectively

b Our proposal: Ir-catalyzed dipolar cycloadditions

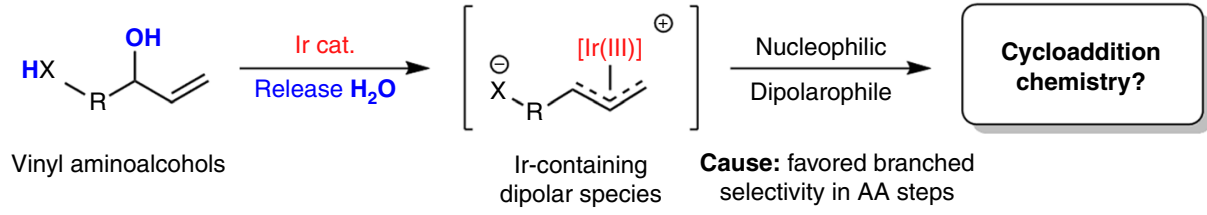

Fig. 1 Research proposal on the Ir-catalyzed cycloadditions of vinyl aminoalcohols. a Well-developed dipolar cycloadditions through asymmetric palladium catalysis and remained problem. b Dipolar cycloadditions through asymmetric iridium catalysis 


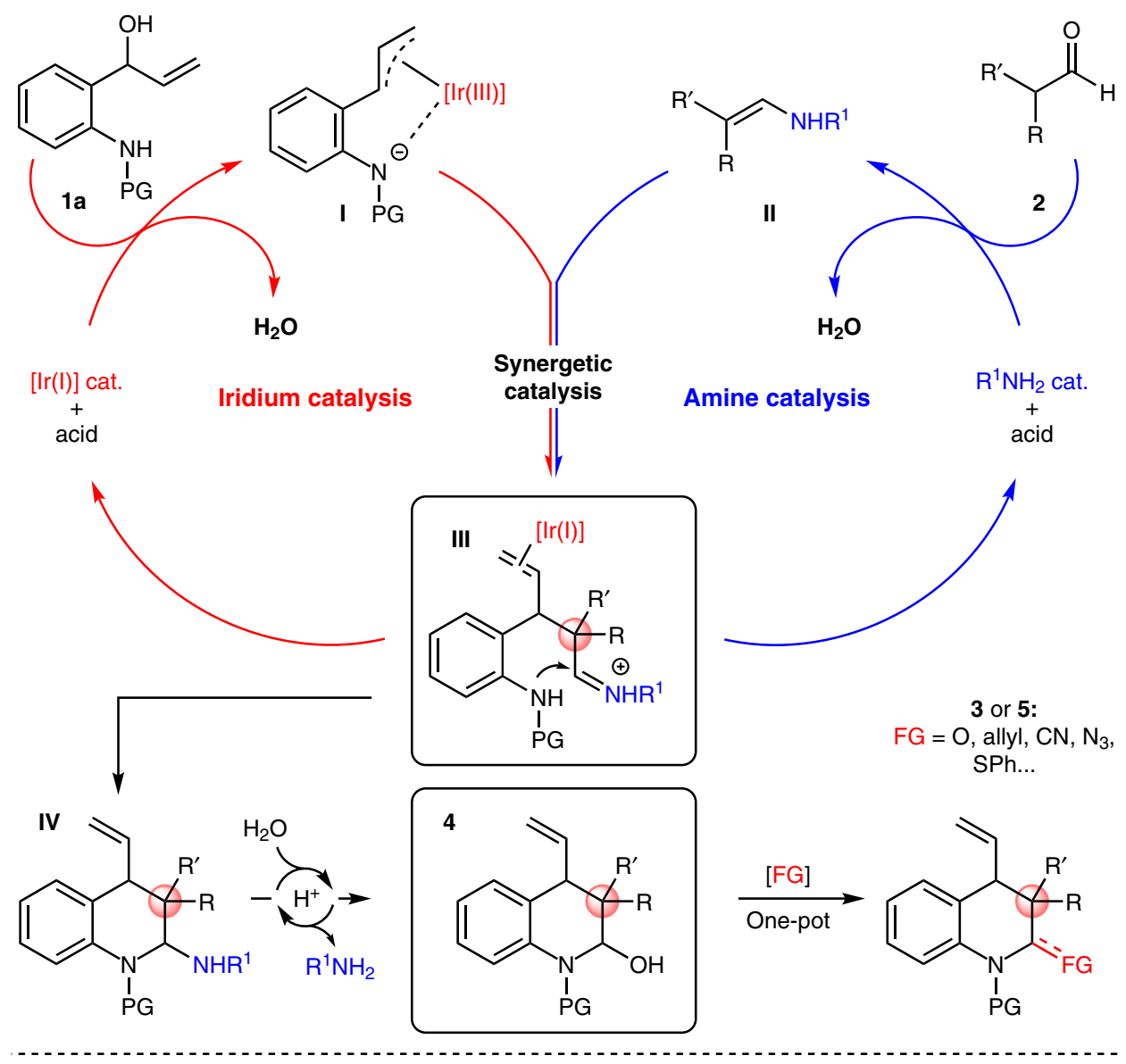

Challenges: $\bullet$ stereochemical control $\bullet$ compatibility problem

Fig. 2 Proposed mechanism. Synergetic iridium/amine catalysis for the enantioconvergent syntheses of hydroquinolines

catalyst $\left(2 \mathrm{~mol} \%\right.$ of $\left[\operatorname{Ir}(\operatorname{cod}) \mathrm{Cl}_{2}\right.$ and $8 \mathrm{~mol} \%$ of Carreira ligand L1) and $20 \mathrm{~mol} \%$ of amine catalyst A1, together with 0.5 eq. of $\mathrm{CCl}_{3} \mathrm{CO}_{2} \mathrm{H}$ and 1.0 eq. of $\mathrm{H}_{2} \mathrm{O}$ as additives, gave hemiaminal $4 \mathbf{a a}$ as a white solid in $92 \%$ yield; 4 aa can be further oxidized to desired hydroquinone 3aa by PCC in $67 \%$ yield with $99 \%$ ee and >19:1 dr. The absolute configuration of product 3aa was determined by comparing the chiral HPLC spectra with a previous literature ${ }^{55}$. To circumvent the isolation of intermediate 4aa, we adopted an improved procedure that simply combined these two processes in one pot. To our delight, quinolinone product 3aa was successfully generated with good reaction efficiency and excellent enantiocontrol under the standard conditions (Table 1, entry 1: $64 \%$ yield, $>99 \%$ ee and $>19: 1 \mathrm{dr}$ ). We then found that the protecting group on the nitrogen atom of the vinyl aminoalcohol had a substantial effect on the reaction selectivity. For example, when Boc-protected substrate $\mathbf{1 a}^{\prime}$ was used instead of 1a, we only identified the byproduct from the allylation of $\mathrm{CCl}_{3} \mathrm{CO}_{2} \mathrm{H}$ (Table 1, entry 2). It is worthy to note that, we have proven that the Ts group on product 3aa could be facilely removed by treatment with Mg powder in methanol (See Supplementary Procedure K). When vinyl aminoalcohol 1a" was tested, there was almost no conversion of starting materials (Table 1, entry 3). Furthermore, the effects of the acid and water as additives were investigated (Table 1, entries 4-7). $\mathrm{CCl}_{3} \mathrm{CO}_{2} \mathrm{H}$ provided superior chemo- and enantioselectivities, and the addition of 1 eq. of water increased the reaction efficiency. Considering that the amine catalyst may play a key role in this reaction, various amine catalysts were examined. As shown in Table 1, a bulkier amine, a, $\alpha$-dimethyl benzylamine (Table 1 , entry 8, A2), gave only 22\% yield, albeit with $>19: 1 \mathrm{dr}$ and $>99 \%$ ee. In addition, when chiral amine catalysts $(\boldsymbol{R})$-A3 and (S)-A3 were applied, we did not observe stereodivergent products, but the different amines did result in different reaction efficiencies (Table 1 entries 9 and 10).

Substrate scope. Having established the optimal conditions, we started to explore the generality of the vinyl aminoalcohol substrate. As summarized in Table 2, a wide range of vinyl aminoalcohols with electron-donating and electron-withdrawing groups, such as $\mathrm{Me}, \mathrm{F}$, and $\mathrm{CF}_{3}$, at the 5-position of the phenyl ring can readily react with aldehyde $2 \mathrm{a}$ to afford the desired dihydro-quinolinone products in moderate yields over two steps with high diastereo- and enantioselectivities (Table 2, entries 1-4, 3aa-3da: $59-66 \%$ yields, 6:1 $\rightarrow 19: 1 \mathrm{dr}$ and $94-99 \%$ ee). Furthermore, substrates with different substitution patterns, for example, 4- $\mathrm{MeO}, 4-\mathrm{Cl}$, and 6-F, were compatible with this asymmetric cycloaddition. The corresponding cycloadducts were achieved in satisfactory reaction efficiencies and stereoselectivities (Table 2, entries 5-7, 3ea-3ga: $61-73 \%$ yields, $12: 1 \rightarrow 19: 1 \mathrm{dr}$ and $98-99 \%$ ee). An allyl alcohol bearing a naphthyl moiety was also suitable for this reaction, and it was converted to product 3 ha in $63 \%$ yield, $12: 1 \mathrm{dr}$ and $98 \%$ ee (Table 2, entry 8 ).

Subsequently, we explored an array of $\alpha$-disubstituted aldehydes in this Ir- and amine-catalyzed cycloaddition/oxidation procedure. As summarized in Fig. 3, the introduction of various groups at the para- or meta-positions of the 2-phenylpropanal was well tolerated in this reaction, and corresponding products 3ab-3ai were obtained in good yields ( $55 \%-75 \%$ yields) and with 
Table 1 Optimization of the reaction conditions for the $[4+2]$ cycloaddition of vinyl aminoalcohols and aldehydes ${ }^{a}$

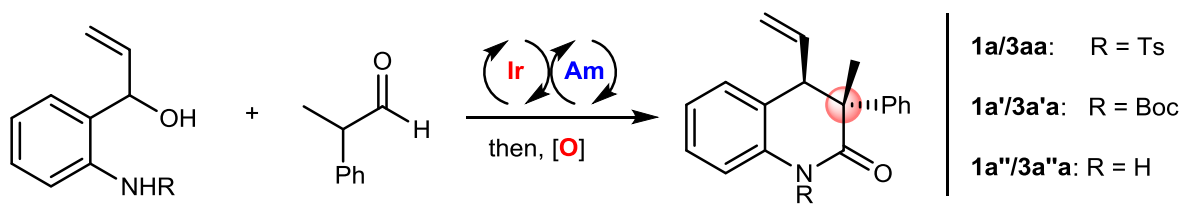

$1 \mathrm{a}, 1 a^{\prime}$ or $1 a^{\prime \prime}$

2a

3aa, 3a'a or 3a"a

\begin{tabular}{llll}
\hline Entry & Variation from the standard conditions & Yield (\%) & ee $\mathbf{( \% '}^{\mathbf{c}}$ \\
\hline 1 & none & 64 & 99 \\
2 & replace $\mathbf{1 a}$ with $\mathbf{1 a}$ & $/$ \\
3 & replace $\mathbf{1 a}$ with $\mathbf{1 a}^{\prime \prime}$ & 0 & $/$ \\
4 & replace $\mathrm{CCl}_{3} \mathrm{CO}_{2} \mathrm{H}$ with $\mathrm{CF}_{3} \mathrm{CO}_{2} \mathrm{H}$ & 0 & 82 \\
5 & replace $\mathrm{CCl}_{3} \mathrm{CO}_{2} \mathrm{H}$ with $\left(\mathrm{PhO}_{2} \mathrm{PO}_{2} \mathrm{H}\right.$ & 63 & 98 \\
6 & replace $\mathrm{CCl}_{3} \mathrm{CO}_{2} \mathrm{H}$ with $\mathrm{PhCO}_{2} \mathrm{H}$ & 58 & $/$ \\
7 & no $\mathrm{H}_{2} \mathrm{O}$ & 0 & 99 \\
8 & replace $\mathbf{A 1}$ with $\mathbf{A 2}$ & 56 & 95 \\
9 & replace $\mathbf{A 1}$ with $(\boldsymbol{R})-\mathbf{A 3}$ & 22 & 93 \\
10 & replace $\mathbf{A 1}$ with (S)-A3 & 62 & 94
\end{tabular}<smiles>C1=Cc2ccccc2N(p2oc3ccc4ccccc4c3c3c(ccc4ccccc43)o2)c2ccccc21</smiles>

(R)-L1<smiles>NC(c1ccccc1)c1ccccc1</smiles>

A1<smiles>CC(C)(N)c1ccccc1</smiles>

A2<smiles>CC(N)c1ccc2ccccc2c1</smiles>

(R)-A3; (S)-A3

Ts $p$-toluene sulfonyl, Boc t-butyloxycarbonyl, PCC pyridinium chlorochromate, Am amine catalyst

astandard conditions: 1a $(0.25 \mathrm{mmol}), \mathbf{2 a}(0.5 \mathrm{mmol})$, $[\mathrm{lr}(\mathrm{cod}) \mathrm{Cl}]_{2}(2 \mathrm{~mol} \%),(\boldsymbol{R})-\mathbf{L 1}(8 \mathrm{~mol} \%)$, amine $\mathbf{A 1}(20 \mathrm{~mol} \%), \mathrm{CCl}_{3} \mathrm{CO}_{2} \mathrm{H}(0.5 \mathrm{eq}$. $)$ and $\mathrm{H}_{2} \mathrm{O}(1.0 \mathrm{eq}$.$) in 1,2-$ dichloroethane $(0.5 \mathrm{~mL})$ for $48 \mathrm{~h}$ at room temperature; then, $\mathrm{PCC}\left(5.0\right.$ eq.), silica gel $(100 \mathrm{mg})$ and $\mathrm{CH}_{2} \mathrm{Cl}_{2}(5 \mathrm{~mL})$ were added, and the mixture was stirred at $40{ }^{\circ} \mathrm{C}$ for $10 \mathrm{~h}$

blsolated yield

'Determined by chiral HPLC analysis; dr > 19:1

Table 2 Synthesis of Dihydroquinolinones form Various Vinyl Aminoalcoholsa<smiles>C=CC(O)c1ccccc1N[13CH3]</smiles>

1: $\mathbf{R}^{\mathbf{1}}$

1a: $\mapsto$

1b: $5-\mathrm{Me}$

1c: $5-\mathrm{F}$

1d: $5-\mathrm{CF}_{3}$

1e: $4-\mathrm{MeO}$

1f: $4-\mathrm{Cl}$

1g: $6-\mathrm{F}$<smiles>CC(C=O)c1ccccc1</smiles>

2a

3aa

3aa

3ba

3da

3ea

$3 f a$

3ga<smiles>C=C[C@H]1c2cc3ccccc3cc2N(C)C(=O)[C@]1(C)c1ccccc1</smiles>

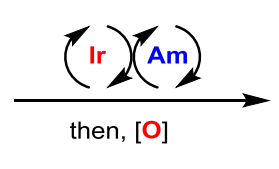

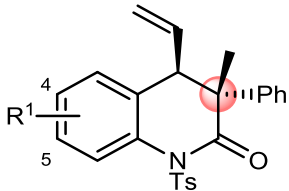

3

\begin{tabular}{lll} 
Yield (\%) & $\mathbf{d r}^{\mathbf{b}}$ & ee (\%) \\
\hline 64 & $>19: 1$ & 99 \\
59 & $16: 1$ & 96 \\
59 & $8: 1$ & 94 \\
66 & $6: 1$ & 98 \\
61 & $19: 1$ & 99 \\
60 & $12: 1$ & 99 \\
73 & $>19: 1$ & 99 \\
63 & $12: 1$ & 98 \\
& & \\
& &
\end{tabular}

3ha: 


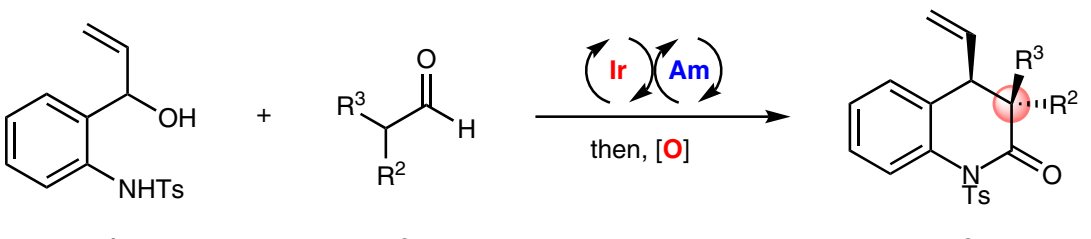

$1 a$

2

3
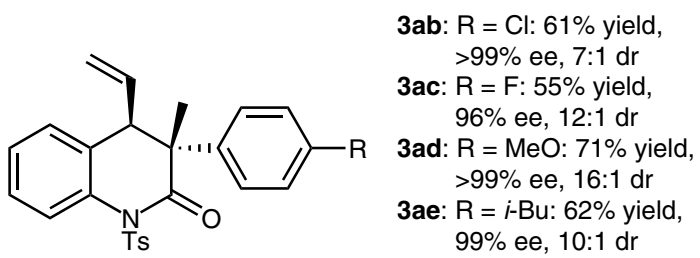

3ab: $\mathrm{R}=\mathrm{Cl}: 61 \%$ yield, $>99 \%$ ee, $7: 1 \mathrm{dr}$

3ac: $R=F: 55 \%$ yield, $96 \%$ ee, $12: 1 \mathrm{dr}$

3ad: $\mathrm{R}=\mathrm{MeO}: 71 \%$ yield, $>99 \%$ ee, $16: 1 \mathrm{dr}$

3ae: $\mathrm{R}=i$-Bu: $62 \%$ yield, $99 \%$ ee, $10: 1 \mathrm{dr}$<smiles>C=C[C@H]1c2ccccc2NC(=O)[C@]1(C)c1cccc([Tl])c1</smiles>

3af: $\mathrm{R}^{1}=\mathrm{Me}, 73 \%$ yield, $99 \%$ ee, $>19: 1 \mathrm{dr}$

3ag: $\mathrm{R}^{1}=\mathrm{Br}, 63 \%$ yield, $99 \%$ ee, $>19: 1 \mathrm{dr}$

3ah: $\mathrm{R}^{1}=$ OTf, $68 \%$ yield, $98 \%$ ee, $7: 1 \mathrm{dr}$<smiles>C=C[C@H]1c2ccccc2NC(=O)[C@]1(C)c1ccc(-c2ccccc2)cc1</smiles>

3ai: $75 \%$ yield, $99 \%$ ee, $16: 1 \mathrm{dr}$<smiles>C=C[C@H]1c2ccccc2N([As])C(=O)[C@]1(C)c1ccc2c(c1)OCO2</smiles>

3al: $57 \%$ yield, $>99 \%$ ee, $19: 1 \mathrm{dr}$<smiles>C=C[C@@H]1c2ccccc2N(C)C(=O)[C@@]1(C)c1ccc2ccccc2c1</smiles>

3aj: $75 \%$ yield, $98 \%$ ee, $16: 1 \mathrm{dr}$<smiles>C=C[C@H]1c2ccccc2N([13CH3])C(=O)[C@]1(C)c1ccc2cc(OC)ccc2c1</smiles>

3ak: $71 \%$ yield, $98 \%$ ee, $>19: 1 \mathrm{dr}$<smiles>C=C[C@H]1c2ccccc2N(C)C(=O)[C@]1(C)C1=C[NH+](S)c2ccccc21</smiles>

3am: $56 \%$ yield, $>99 \%$ ee, $>19: 1 \mathrm{dr}$<smiles>C=C[C@@H]1c2ccccc2N([As])C(=O)C12CCCC2</smiles>

3an $(n=1): 64 \%$ yield, $>99 \%$ ee 3ao $(n=2): 74 \%$ yield, $>99 \%$ ee<smiles>C=C[C@H]1c2ccccc2N([As])C(=O)[C@]1(C)Cc1ccccc1</smiles>

3ap: $77 \%$ yield, $>99$ />99\% ee, $2.5: 1 \mathrm{dr}$

Fig. 3 Synthesis of dihydroquinolinones from various aldehydes. Reaction conditions: as indicated in entry 1 in Table 1; isolated yield; the ee and dr values were determined by chiral HPLC analysis

high stereoselectivities (up to $>19: 1 \mathrm{dr}$ and $96 \rightarrow 99 \%$ ee). Moreover, aldehydes with naphthalene and other polycyclic systems can be converted to corresponding dihydro-quinolinones 3aj-3am in good yields and excellent enantioselectivities (56-75\% yields and up to $>99 \%$ ee). Notably, an indole-derived substrate was also well tolerated in this reaction and provided a good result (3am, 56\% yield, $>19: 1 \mathrm{dr}$ and $>99 \%$ ee). In addition, cyclic aldehydes with various ring sizes (i.e., five- or six-membered rings) could readily participate in this reaction (3an, 64\% yield, >99\% ee; 3ao, $74 \%$ yield, $>99 \%$ ee). A dialkyl-substituted acetaldehyde, 2-methyl-3-phenylpropanal, could also be reacted under these conditions to give the desired product 3ap in a good yield and with an excellent enantioselectivity. A linear aldehyde, $n$-butanal, was also proven suitable for this transformation, affording dihydroquinolinone product 3ar in 31\% yield, $>99 \%$ ee and >20:1 dr (See Supplementary Procedure M).

Demonstrations of synthetic utility. To illustrate the versatility of this cycloaddition, we explored various derivatizations of the hemiaminal intermediate. As highlighted in Fig. 4, taking key hemiaminal 4aq ( $>99 \%$ ee and 5:1 dr), which was generated from the asymmetric cycloaddition of vinyl aminoalcohol 1a and isobutyraldehyde $\mathbf{2 q}$, as an example, treatment with various organic reagents in one-pot reactions indeed provided a diverse set of functionalized hydroquinolines in generally high yields and excellent enantioselectivities. Except in the oxidation with
PCC, the $\mathrm{OH}$ group of hemiaminal 4 aq could be removed by treating the compound with $\mathrm{Et}_{3} \mathrm{SiH}$ and $\mathrm{Et}_{2} \mathrm{O} \cdot \mathrm{BF}_{3}$ in $\mathrm{DCM}$, giving tetrahydroquinoline $\mathbf{5 b}$ in $87 \%$ yield and $>99 \%$ ee. Similarly, replacement of the hydroxyl group with other organosilicon reagents could deliver 2 -allyl-, $2-\mathrm{CN}$ - and $2-\mathrm{N}_{3}$-substituted tetrahydroquinolines 5c-5e in $84-91 \%$ yields and $>99 \%$ ee, albeit with modest $\mathrm{dr}$ values. In addition, the $\mathrm{OH}$ group can be successfully converted to ether or sulfide moieties in good yields and excellent enantioselectivities (5f, 77\% yield, 5:1 dr and $>99 \%$ ee; $5 \mathbf{g}, 76 \%$ yield, $>19: 1 \mathrm{dr}$ and $>99 \%$ ee. The high diastereoselectivity of product $5 \mathrm{~g}$ may be result of the steric effect (See Supplementary Procedures I and J), and its absolute configuration was established through the X-ray diffraction analysis (CCDC 1821791) ${ }^{63}$.

Stereodivergent $[4+2]$ cycloadditions. In addition to activating the $\alpha$-position of the aldehyde via an enamine mechanism ${ }^{64}$, amine catalysis can also be used to efficiently activate the $\gamma$-position of the $\beta, \gamma$-unsaturated ketone through the formation of an dienamine species ${ }^{65-69}$. Based on this information and our above impressive results, we further probed the asymmetric $[4+2]$ cycloadditions of vinyl aminoalcohols with $\beta, \gamma$-unsaturated ketones by merging iridium catalysis with dienamine catalysis. With the cycloaddition of vinyl aminoalcohol 1a and ketone $\mathbf{6}$ as model substrates, a simple optimization of the reaction parameters including chiral amine catalyst, solvent, and acid defined the optimal reaction conditions (See Supplementary Table 3 for the details 
<smiles></smiles>

5g: $76 \%$ yield $>19: 1 \mathrm{dr},>99 \%$ ee<smiles>C=C[C@@H]1c2ccccc2N([As])[C@@H](OCC)C1(C)C</smiles>

5f: $77 \%$ yield, $5: 1 \mathrm{dr},>99 \%$ ee<smiles>C=C[C@@H]1c2ccccc2N([AsH3])[C@H](N)C1(C)C</smiles>

5e: $84 \%$ yield, $4: 1 \mathrm{dr},>99 \%$ ee<smiles>C=CC(O)c1ccccc1N[13F]</smiles>

$2 q$<smiles>C=C[C@H]1c2ccccc2N(C)C(=O)C1(C)C</smiles>

5a: $88 \%$ yield, $>99 \%$ ee<smiles>C=C[C@H]1c2ccccc2N([As])C(C)C1(C)C</smiles>

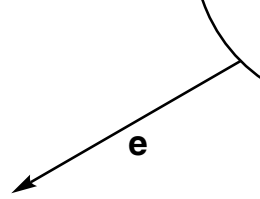

Ts

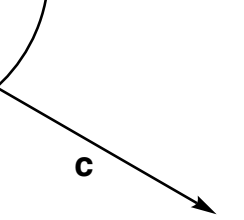

5b: $87 \%$ yield, $>99 \%$ ee

Fig. 4 Divergent synthetic transformations of chiral hemiaminal 4aq. Reaction conditions: a) $\mathrm{PCC}(5.0$ eq. $)$, silica $(100 \mathrm{mg}), \mathrm{CH}_{2} \mathrm{Cl}_{2}(5 \mathrm{~mL}), 40{ }^{\circ} \mathrm{C}, 10 \mathrm{~h}$; b) $\mathrm{Et}_{3} \mathrm{SiH}\left(3.0\right.$ eq.), $\mathrm{Et}_{2} \mathrm{O} \cdot \mathrm{BF}_{3}$ (3.0 eq.), $\mathrm{CH}_{2} \mathrm{Cl}_{2}(3 \mathrm{~mL}), 0^{\circ} \mathrm{C}, 5 \mathrm{~min}$; c) allyltrimethylsilane (3.0 eq.), $\mathrm{Et}_{2} \mathrm{O} \cdot \mathrm{BF}_{3}(3.0$ eq. $), \mathrm{CH}_{2} \mathrm{Cl}_{2}(3 \mathrm{~mL}), \mathrm{O}^{\circ} \mathrm{C}, 5 \mathrm{~min}$; d) $\operatorname{TMSCN}\left(2.0\right.$ eq.), $\mathrm{Et}_{2} \mathrm{O} \cdot \mathrm{BF}_{3}$ (3.0 eq.), $\mathrm{CH}_{2} \mathrm{Cl}_{2}\left(3 \mathrm{~mL}\right.$ ), $0^{\circ} \mathrm{C}, 5 \mathrm{~min}$; e) $\mathrm{TMSN}_{3}\left(2.0\right.$ eq.), $\mathrm{Et}_{2} \mathrm{O} \cdot \mathrm{BF}_{3}\left(3.0\right.$ eq.), $\mathrm{CH}_{2} \mathrm{Cl}_{2}\left(3 \mathrm{~mL}\right.$ ), $\left.0^{\circ} \mathrm{C}, 5 \mathrm{~min} ; \mathbf{f}\right) p-\mathrm{TSA}^{\circ}$ (20 mol\%), $\mathrm{EtOH}(2.5 \mathrm{~mL}), 30^{\circ} \mathrm{C}, 10$ h. g) PhSH (1.5 eq.), $\mathrm{Et}_{2} \mathrm{O} \cdot \mathrm{BF}_{3}$ (3.0 eq.), $\mathrm{CH}_{2} \mathrm{Cl}_{2}(3 \mathrm{~mL}), 0^{\circ} \mathrm{C}, 5 \mathrm{~min}$; isolated yield; the ee and dr values were determined by chiral HPLC analysis of purified products and ${ }^{1} \mathrm{H}$ NMR analysis of reaction mixtures, respectively. $p$-TSA: $p$-toluenesulfonic acid

of condition optimization). To our delight, unlike the cycloaddition of vinyl aminoalcohols 1 with aldehyde 2 , which provides a pair of diastereomers, by reasonably using Carreira's chiral phosphoramidite ligands, $(\boldsymbol{R})$-L1 or $(S)$-L1, and Luo's primary amine catalyst $(S)-\mathrm{A4}^{70}$, this reaction can provide both members of either of two pairs of diastereomers in good yields and with excellent enantioand diastereoselectivities (Fig. 5, (R,R)-7a, 84\% yield, $>99 \%$ ee and $>19: 1 \mathrm{dr}$; $(\boldsymbol{R}, S)-7 \mathbf{a}, 81 \%$ yield, $>99 \%$ ee and $>19: 1 \mathrm{dr})$. Worthy to note that, other two stereoisomers of $7 \mathbf{a}$ have been synthesized by using the enantiomer of Luo's catalyst $(S)$-A4, too (See Supplementary Table 3 for details). The absolute configuration of product $(R, S)$-7a were established by analyzing its derivative through the Xray diffraction analysis (CCDC 1869868, See Supplementary Note 1 for details $)^{25}$. Encouraged by these results, experiments to preliminarily examine the scope of vinyl aminoalcohols for this stereodivergent cycloaddition were performed. As highlighted in Fig. 4, moderate to good yields together with high levels of enantio- and diastereocontrol were generally observed for both pairs of diastereomers. In a word, this is an interesting but challenging work that high diastereo- and enantioselectivities have been simultaneously accomplished in a stereodivergent manner, demonstrating the power and potential of synergetic catalysis strategies in the field of TM-catalyzed dipolar cycloaddition.

\section{Discussion}

Overall, we have successfully developed two enantioselective $[4+2]$ cycloadditions of vinyl aminoalcohols with carbonyls, namely, aldehydes and $\beta, \gamma$-unsaturated ketones, through synergetic iridium and amine catalysis. The cycloaddition with aldehydes provides a diverse set of hydroquinolines bearing chiral quaternary stereocenters with a high level of enantiocontrol. The reaction with $\beta, \gamma$-unsaturated ketones allows the enantio- and diastereodivergent synthesis of hydroquinoline products using reasonable chiral iridium catalysts and chiral amine catalysts. Obviously, the formation of Ir-containing dipoles from vinyl aminoalcohols and chiral iridium catalysts and (di)enamine dipolarophiles from carbonyls and amine catalysts provides a foundation for subsequent asymmetric [4+2] dipolar cycloadditions. As demonstrated in this work, the application of synergetic catalysis makes transition metal-catalyzed cycloadditions more practical and powerful for the synthesis of chiral heterocycles.

\section{Methods}

Preparation of product 3. In a dried Schlenk tube under $\mathrm{N}_{2},\left[\operatorname{Ir}(\operatorname{cod}) \mathrm{Cl}_{2}(0.005\right.$ $\mathrm{mmol}, 3.35 \mathrm{mg})$ and chiral ligand $(\boldsymbol{R})-\mathbf{L} \mathbf{1}(0.02 \mathrm{mmol}, 10.15 \mathrm{mg})$ were mixed in 0.5 $\mathrm{mL}$ DCE and stirred at ambient temperature for $20 \mathrm{~min}$ under argon atmosphere Then allylic alcohol $1(0.25 \mathrm{mmol}, 1.0 \mathrm{eq})$, aldehyde $2(0.5 \mathrm{mmol}, 2.0 \mathrm{eq})$, $\mathrm{Cl}_{3} \mathrm{CCOOH}(0.125 \mathrm{mmol}, 20.4 \mathrm{mg})$, amine $\mathbf{A 1}(0.05 \mathrm{mmol}, 9.2 \mathrm{mg}, 8.7 \mu \mathrm{L}), 4.5 \mu \mathrm{L}$ $\mathrm{H}_{2} \mathrm{O}$ (1.0 eq.) were added to the mixture successively. The reaction mixture was stirred at ambient temperature until substrate 1 disappeared on TLC. Then the mixture was diluted with $5 \mathrm{~mL}$ DCM, PCC $(275 \mathrm{mg}, 5.0$ eq. $)$ and $100 \mathrm{mg}$ silica gel were added to the mixture. The mixture was stirred at $40^{\circ} \mathrm{C}$ for $12 \mathrm{~h}$ and the final product was achieved by flash column chromatography.

Preparation of product 7. In a dried Schlenk tube under $\mathrm{N}_{2},\left[\operatorname{Ir}(\operatorname{cod}) \mathrm{Cl}_{2}(0.005\right.$ $\mathrm{mmol}, 3.35 \mathrm{mg})$ and chiral ligand $(\boldsymbol{R})-\mathbf{L}$ or $(\boldsymbol{S})-\mathbf{L} \mathbf{1}(0.02 \mathrm{mmol}, 10.15 \mathrm{mg})$ were 


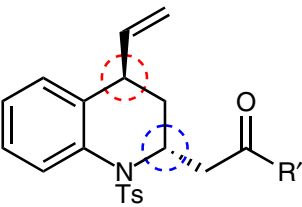

$(R, R)-7$ a: $84 \%$ yield $>99 \%$ ee, dr $>19: 1$

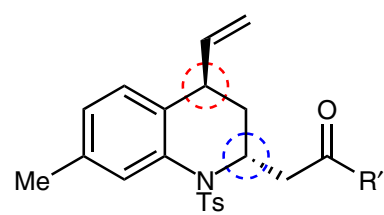

$(R, R)-7 \mathrm{~b}: 57 \%$ yield $>99 \%$ ee, $13: 1 \mathrm{dr}$

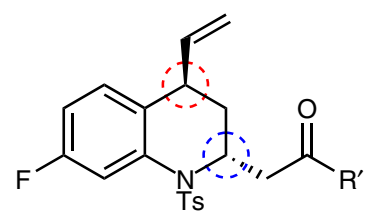

$(R, R)-7 \mathrm{c}: 63 \%$ yield $>99 \%$ ee, $>19: 1 \mathrm{dr}$

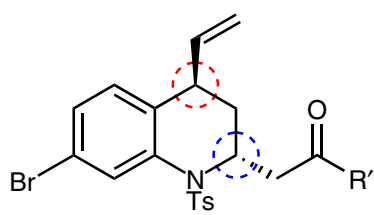

$(R, R)-7 \mathrm{~d}: 81 \%$ yield $>99 \%$ ee, $>19: 1 \mathrm{dr}$

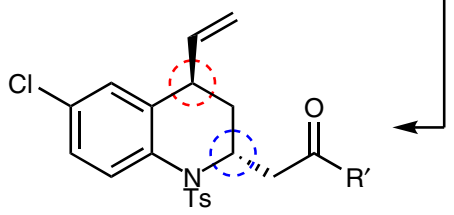

$(R, R)-7 \mathrm{e}: 66 \%$ yield $>99 \%$ ee, $9: 1 \mathrm{dr}$<smiles>C1=Cc2ccccc2N(p2oc3ccc4ccccc4c3c3c(ccc4ccccc43)o2)c2ccccc21</smiles>

(R)-L1 or (S)-L1

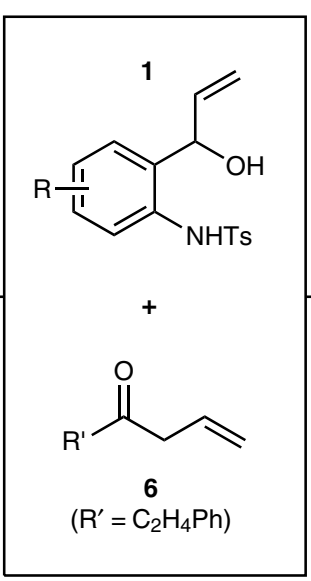<smiles>CCN([O])C[C@H](N)C(C)(C)C</smiles>

(S)-A4

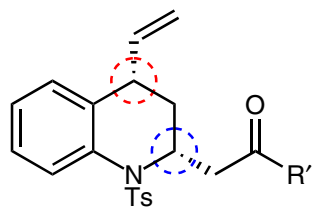

(R,S)-7a: $81 \%$ yield $>99 \%$ ee, $>19: 1 \mathrm{dr}$

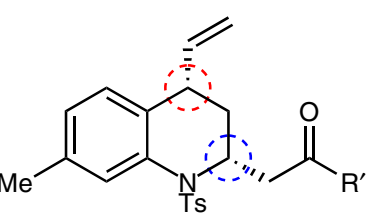

( $R, S)-7 b: 53 \%$ yield $>99 \%$ ee, $>19: 1 \mathrm{dr}$

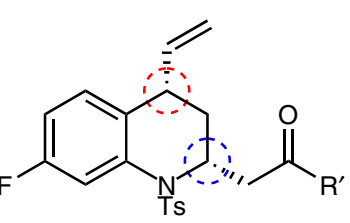

(R,S)-7c: $45 \%$ yield $>99 \%$ ee, $>19: 1 \mathrm{dr}$

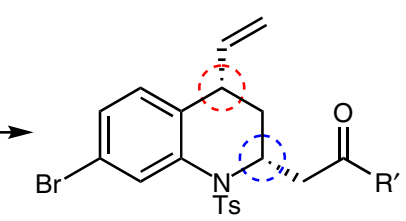

( $R, S)-7 \mathrm{~d}: 74 \%$ yield $>99 \%$ ee, $>19: 1 \mathrm{dr}$

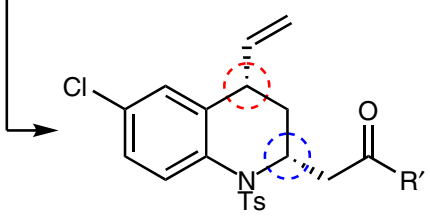

$(R, S)-7 e: 59 \%$ yield $>99 \%$ ee, $>19: 1 \mathrm{dr}$

Fig. 5 Enantioselective and diastereodivergent [4+2] cycloadditions of vinyl aminoalcohols and $\beta, \gamma$-unsaturated ketones. Reaction conditions: 1 ( 0.25 $\mathrm{mmol}), \mathbf{6}(1.25 \mathrm{mmol}),\left[\mathrm{lr}(\mathrm{cod}) \mathrm{Cl}_{2}(2 \mathrm{~mol} \%),(\boldsymbol{R})\right.$ - $\mathbf{L 1}$ or $(\boldsymbol{S})$ - $\mathbf{L 1}(8 \mathrm{~mol} \%)$, amine $(\boldsymbol{S})$-A4 $(20 \mathrm{~mol} \%)$, in 1,2-dichloroethane $(0.3 \mathrm{~mL})$ for $48 \mathrm{~h}$ at $50{ }^{\circ} \mathrm{C}$; isolated yield; the values of ee and dr were determined by chiral HPLC analysis

mixed in $0.3 \mathrm{~mL}$ DCE and stirred at ambient temperature for $20 \mathrm{~min}$ under argon atmosphere. Then allylic alcohol $1(0.25 \mathrm{mmol}, 1.0 \mathrm{eq})$, ketone $2(0.5 \mathrm{mmol}, 2.0 \mathrm{eq})$ and chiral amine catalyst $(S)$-A4 $(0.05 \mathrm{mmol}, 16.1 \mathrm{mg})$ were added to the mixture successively. After $8 \mathrm{~h}$, the other 3.0 eq. ketone 2 was added in portions. Stirring at $50^{\circ} \mathrm{C}$ for $48 \mathrm{~h}$. The residue was directly purified by flash silica gel chromatography to afford the title compound.

\section{Data availability}

The authors declare that the data supporting the findings of this study are available within the article and Supplementary Information file, or from the corresponding author upon reasonable request. The X-ray crystallographic coordinates for structures reported in this study have been deposited at the Cambridge Crystallographic Data Centre (CCDC), under deposition numbers CCDC 1821791 and CCDC 1869868. These data can be obtained free of charge from The Cambridge Crystallographic Data Centre via www.ccdc.cam.ac.uk/data_request/cif.

Received: 18 January 2019 Accepted: 17 May 2019

Published online: 20 June 2019

\section{References}

1. Pozharskii, A. R., Soldatenkov, A. \& Katritzky, A. R. Heterocycles in Life and Society: An Introduction to Heterocyclic Chemistry, Biochemistry and Applications (Willey, 2010).

2. Katritzky, A. R., Ramsden, C. A., Joule, J. A. \& Zhdankin, V. V. Handbook of Heterocyclic Chemistry, Third Edition (Elsevier, 2010).

3. Kusama, H. \& Iwasawa, N. Cycloaddition reactions of transition metalcontaining benzopyrylium and related zwitterionic intermediates. Chem. Lett. 35, 1082-1087 (2006).

4. Xu, X. \& Doyle, M. P. The [3+3]-cycloaddition alternative for heterocycle syntheses: catalytically generated metalloenolcarbenes as dipolar adducts. Acc. Chem. Res. 47, 1396-1405 (2014).

5. De, N. \& Yoo, E. J. Recent advances in the catalytic cycloaddition of 1 , n-dipoles. ACS Catal. 8, 48-58 (2017).

6. Weaver, J. D., Recio, A., Grenning, A. J. \& Tunge, J. A. Transition metalcatalyzed decarboxylative allylation and benzylation reactions. Chem. Rev. 111, 1846-1913 (2011).

7. Allen, B. D. W., Lakeland, C. P. \& Harrity, J. P. A. Utilizing palladiumstabilized zwitterions for the construction of N-heterocycles. Chem. Eur. J. 23, 13830-13857 (2017). 
8. Lowe, M. A. et al. Palladium-mediated annulation of vinyl aziridines with michael acceptors: stereocontrolled synthesis of substituted pyrrolidines and its application in a formal synthesis of (-)-a-kainic acid. Angew. Chem. Int. Ed. 50, 6370-6374 (2011).

9. Shintani, R., Moriya, K. \& Hayashi, T. Guiding the nitrogen nucleophile to the middle: palladium-catalyzed decarboxylative cyclopropanation of 2alkylidenetrimethylene carbonates with isocyanates. Chem. Commun. 47, 3057-3059 (2011).

10. Ohmatsu, K., Imagawa, N. \& Ooi, T. Ligand-enabled multiple absolute stereocontrol in metal-catalysed cycloaddition for construction of contiguous all-carbon quaternary stereocentres. Nat. Chem. 6, 47-51 (2013).

11. Khan, A. et al. Palladium-catalyzed decarboxylative cycloaddition of vinylethylene carbonates with formaldehyde: enantioselective construction of tertiary vinylglycols. Angew. Chem. Int. Ed. 53, 6439-6442 (2014).

12. Xu, C.-F., Zheng, B.-H., Suo, J.-J., Ding, C.-H. \& Hou, X.-L. Highly diastereoand enantioselective palladium-catalyzed $[3+2]$ cycloaddition of vinyl aziridines and $\alpha, \beta$-unsaturated ketones. Angew. Chem. Int. Ed. 54, 1624-1627 (2014).

13. Poli G., Prestat G., Liron F. \& Kammerer-Pentier C. Selectivity in PalladiumCatalyzed Allylic Substitution. In Transition Metal Catalyzed Enantioselective Allylic Substitution in Organic Synthesis. Topics in Organometallic Chemistry, (eds Kazmaier, U.) vol. 38. (Springer, Berlin, Heidelbe 2011).

14. Wang, Y.-N., Lu, L.-Q. \& Xiao, W.-J. Non-bonding interactions enable the selective formation of branched products in palladium-catalyzed allylic substitution reactions. Chem. Asian J. 13, 2174-2183 (2018).

15. Li, T.-R. et al. Asymmetric trapping of zwitterionic intermediates by sulphur ylides in a palladium-catalysed decarboxylation-cycloaddition sequence. Nat. Commun. 5, 5500-5509 (2014).

16. Guo, C., Fleige, M., Janssen-Mgller, D., Daniliuc, C. G. \& Glorius, F. Cooperative N-heterocyclic carbene/palladium-catalyzed enantioselective umpolung annulations. J. Am. Chem. Soc. 138, 7840-7843 (2016).

17. Guo, C. et al. Mechanistic studies on a cooperative NHC organocatalysis/ palladium catalysis system: uncovering significant lessons for mixed chiral $\mathrm{Pd}(\mathrm{NHC})\left(\mathrm{PR}_{3}\right)$ catalyst design. J. Am. Chem. Soc. 139, 4443-4451 (2017).

18. Mei, G.-J. et al. Catalytic asymmetric construction of the tryptanthrin skeleton via an enantioselective decarboxylative $[4+2]$ cyclization. Org. Lett. 19, 3219-3222 (2017).

19. Singha, S., Patra, T., Daniliuc, C. G. \& Glorius, F. Highly enantioselective $[5+2]$ annulations through cooperative N-heterocyclic carbene (NHC) organocatalysis and palladium catalysis. J. Am. Chem. Soc. 140, 3551-3554 (2018).

20. Takeuchi, R. \& Kashio, M. Highly selective allylic alkylation with a carbon nucleophile at the more substituted allylic terminus catalyzed by an iridium complex: an efficient method for constructing quaternary carbon centers. Angew. Chem. Int. Ed. 36, 263-264 (1997)

21. Janssen, J. P. \& Helmchen, G. First enantioselective alkylations of monosubstituted allylic acetates catalyzed by chiral iridium complexes. Tetrahedron Lett. 38, 8025-8026 (1997).

22. Takeuchi, R. \& Kashio, M. Iridium complex-catalyzed allylic alkylation of allylic esters and allylic alcohols: unique regio- and stereoselectivity. J. Am. Chem. Soc. 120, 8647-8655 (1998).

23. Qu, J. \& Helmchen, G. Applications of iridium-catalyzed asymmetric allylic substitution reactions in target-oriented synthesis. Acc. Chem. Res. 50, 2539-2555 (2017).

24. Hartwig, J. F. \& Levi, M. Stanley mechanistically driven development of iridium catalysts for asymmetric allylic substitution. Acc. Chem. Res. 43, 1461-1475 (2010).

25. Krautwald, S. \& Carreira, E. M. Stereodivergence in asymmetric catalysis. J. Am. Chem. Soc. 139, 5627-5639 (2017).

26. Zhuo, C.-X., Zheng, C. \& You, S.-L. Transition-metal-catalyzed asymmetric allylic dearomatization reactions. Acc. Chem. Res. 47, 2558-2573 (2014).

27. Lu, Z. \& Ma, S. Metal-catalyzed enantioselective allylation in asymmetric synthesis. Angew. Chem. Int. Ed. 47, 258-297 (2008).

28. Liu, W.-B., Xia, J.-B. \& You, S.-L. Iridium-catalyzed asymmetric allylic substitutions. Top. Organomet. Chem. 38, 155-208 (2012).

29. Hartwig, J. F. \& Pouy, M. J. Iridium-catalyzed allylic substitution. Top. Organomet. Chem. 34, 169-208 (2011).

30. Helmchen, G. Iridium-Catalyzed Allylic Substitutions, Iridium Complexes in Organic Synthesis. (eds Oro, L. A. \& Claver, G.) pp 211-250 (Willey, 2009).

31. Kanayama, T., Yoshida, K., Miyabe, H., Kimachi, T. \& Takemoto, Y. Synthesis of $\beta$-substituted $\alpha$-amino acids with use of iridium-catalyzed asymmetric allylic substitution. J. Org. Chem. 68, 6197-6201 (2003).

32. Krautwald, S., Sarlah, D., Schafroth, M. A. \& Carreira, E. M. Enantio- and diastereodivergent dual catalysis: $\alpha$-allylation of branched aldehydes. Science 340, 1065-1068 (2013)

33. Krautwald, S., Schafroth, M. A., Sarlah, D. \& Carreira, E. M. Stereodivergent a-allylation of linear aldehydes with dual iridium and amine catalysis. J. Am. Chem. Soc. 136, 3020-3023 (2014).
34. Næsborg, L., Halskov, K. S., Tur, F., Mønsted, S. M. N. \& Jørgensen, K. A. Asymmetric $\gamma$-allylation of $\alpha, \beta$-unsaturated aldehydes by combined organocatalysis and transition-metal catalysis. Angew. Chem. Int. Ed. 54, 10193-10197 (2015).

35. Jiang, X., Beiger, J. J. \& Hartwig, J. F. Stereodivergent allylic substitutions with aryl acetic acid esters by synergistic iridium and lewis base catalysis. J. Am. Chem. Soc. 139, 87-90 (2017).

36. Shen, D., Chen, Q., Yan, P., Zeng, X. \& Zhong, G. Enantioselective dearomatization of naphthol derivatives with allylic alcohols by cooperative iridium and Brønsted acid catalysis. Angew. Chem. Int. Ed. 56, 3242-3246 (2017).

37. Huo, X., He, R., Zhang, X. \& Zhang, W. An Ir/Zn dual catalysis for enantioand diastereodivergent $\alpha$-allylation of $\alpha$-hydroxyketones. J. Am. Chem. Soc 138, 11093-11096 (2016).

38. Jiang, X., Boehm, P. \& Hartwig, J. F. Stereodivergent allylation of azaaryl acetamides and acetates by synergistic iridium and copper catalysis. J. Am. Chem. Soc. 140, 1239-1242 (2018).

39. Wei, L., Zhu, Q., Xu, S.-M., Chang, X. \& Wang, C.-J. Stereodivergent synthesis of $\alpha, \alpha$-disubstituted $\alpha$-amino acids via synergistic $\mathrm{Cu} / \mathrm{Ir}$ catalysis. J. Am. Chem. Soc. 140, 1508 (2018).

40. Huo, X., Zhang, J., Fu, J., He, R. \& Zhang, W. Ir/Cu dual catalysis: enantioand diastereodivergent access to $\alpha, \alpha$-disubstituted $\alpha$-amino acids bearing vicinal stereocenters. J. Am. Chem. Soc. 140, 2080-2084 (2018).

41. Zhang, M.-M., Luo, Y.-Y., Lu, L.-Q. \& Xiao, W.-J. Advances on asymmetric allylic substitutions under synergetic catalysis system with transition metals and organocatalysts. Acta Chim. Sin. 76, 838-849 (2018).

42. Sridharan, V., Suryavanshi, P. A. \& Mendez, J. C. Advances in the chemistry of tetrahydroquinolines. Chem. Rev. 111, 7157-7259 (2011).

43. Gómez, C. M. M. \& Kouznetsov, V. Recent Development on Antimicrobial Quinoline Chemistry, in Microbial Pathogens and Strategies for Combating Them: Science Technology and Educations vol. 1A. (eds Mendez-Vilas), pp 666-677 (Formatex, Badajoz, 2013).

44. Liu, W.-B., Zheng, C., Zhuo, C.-X., Dai, L.-X. \& You, S.-L. Iridium-catalyzed allylic alkylation reaction with $\mathrm{N}$-aryl phosphoramidite ligands: scope and mechanistic studies. J. Am. Chem. Soc. 134, 4812-4821 (2012).

45. Wang, C. \& Tunge, J. A. Asymmetric cycloadditions of palladium-polarized aza-o-xylylenes. J. Am. Chem. Soc. 130, 8118-8119 (2008).

46. Zhang, X. et al. An organocatalytic cascade approach toward polysubstituted quinolines and chiral 1,4-dihydroquinolines-unanticipated effect of $\mathrm{N}$ protecting groups. Angew. Chem. Int. Ed. 51, 7282-7286 (2012).

47. Leth, L. A. et al. Decarboxylative [4+2] Cycloaddition by synergistic palladium and organocatalysis. Angew. Chem. Int. Ed. 55, 15272-15276 (2016).

48. Fu, Z., Jiang, K., Zhu, T., Torres, J. \& Chi, Y.-R. Access to oxoquinoline heterocycles by $\mathrm{N}$-heterocyclic carbene catalyzed ester activation for selective reaction with an enone. Angew. Chem. Int. Ed. 53, 6506-6510 (2014).

49. Song, J., Zhang, Z.-J. \& Gong, L.-Z. Asymmetric [4+2] annulation of c1 ammonium enolates with copper-allenylidenes. Angew. Chem. Int. Ed. 56, 5212-5216 (2017)

50. Lu, L.-Q., Li, T.-R., Wang, Q. \& Xiao, W.-J. Beyond sulfide-centric catalysis: recent advances in the catalytic cyclization reactions of sulfur ylides. Chem. Soc. Rev. 46, 4135-4149 (2017).

51. Li, T.-R., Wang, Y.-N., Xiao, W.-J. \& Lu, L.-Q. Transition-metal-catalyzed cyclization reactions using vinyl and ethynyl benzoxazinones as dipole precursors. Tetrahedron Lett. 59, 1521-1530 (2018).

52. Wang, Q. et al. Catalytic asymmetric [4+1] annulation of sulfur ylides with copper-allenylidene intermediates. J. Am. Chem. Soc. 138, 8360-8363 (2016).

53. Wei, Y. et al. P,S ligands for the asymmetric construction of quaternary stereo centers in palladium-catalyzed decarboxylative [4+2] cycloadditions. Angew. Chem. Int. Ed. 55, 2200-2204 (2016).

54. Wang, Q. et al. Iron-catalyzed decarboxylative $(4+1)$ cycloadditions: exploiting the reactivity of ambident iron-stabilized intermediates. Angew. Chem. Int. Ed. 55, 2840-2844 (2016).

55. Li, M.-M. et al. Sequential visible-light photoactivation and palladium catalysis enabling enantioselective [4+2] cycloadditions. J. Am. Chem. Soc. 139, 14707 (2017).

56. Liang, X. et al. Ir-catalyzed asymmetric total synthesis of (-)-communesin F. J. Am. Chem. Soc. 139, 3364-3367 (2018).

57. Sandmeier, T., Krautwald, S. \& Carreira, E. M. Stereoselective synthesis of piperidines by iridium-catalyzed cyclocondensation. Angew. Chem. Int. Ed. 56, 11515-11519 (2017).

58. Quasdorf, K. W. \& Overman, L. E. Catalytic enantioselective synthesis of quaternary carbon stereocentres. Nature 516, 181-191 (2014).

59. Liu, Y., Han, S. J., Liu, W.-B. \& Stoltz, B. M. Catalytic enantioselective construction of quaternary stereocenters: assembly of key building blocks for the synthesis of biologically active molecules. Acc. Chem. Res. 48, 740-751 (2015). 
60. Mukherjee, S. \& List, B. Chiral counteranions in asymmetric transition-metal catalysis: highly enantioselective $\mathrm{Pd} /$ Brønsted acid-catalyzed direct $\alpha$-allylation of aldehydes. J. Am. Chem. Soc. 129, 11336-11337 (2007).

61. Yoshida, M., Terumine, T., Masaki, E. \& Hara, S. Direct asymmetric $\alpha$-allylation of $\alpha$-branched aldehydes by two catalytic systems with an achiral Pd complex and a chiral primary a-amino acid. J. Org. Chem. 78, 10853-10859 (2013).

62. Wang, P.-S., Lin, H.-C., Zhai, Y.-J., Han, Z.-Y. \& Gong, L.-Z. Chiral counteranion strategy for asymmetric oxidative $\mathrm{C}\left(\mathrm{sp}^{3}\right)-\mathrm{H} / \mathrm{C}\left(\mathrm{sp}^{3}\right)-\mathrm{H}$ coupling: enantioselective $\alpha$-allylation of aldehydes with terminal alkenes. Angew. Chem. Int. Ed. 53, 12218-12221 (2014).

63. Song, W. et al. Iridium-catalyzed highly regioselective and diastereoselective allylic etherification to access cis-2,6-disubstituted dihydropyridinones. J. Org. Chem. 83, 12822-12830 (2018).

64. Mukherjee, S., Yang, J.-W., Hoffmann, S. \& List, B. Asymmetric enamine catalysis. Chem. Rev. 107, 5471-5569 (2007).

65. Bertelsen, S., Marigo, M., Brandes, S., Dinér, P. \& Jørgensen, K. A. Dienamine catalysis: organocatalytic asymmetric $\gamma$-amination of $\alpha, \beta$-unsaturated aldehydes. J. Am. Chem. Soc. 128, 12973-1298 (2006).

66. Li, J.-L., Liu, T.-Y. \& Chen, Y.-C. Aminocatalytic asymmetric Diels-Alder reactions via homo activation. Acc. Chem. Res. 45, 1491-1500 (2012)

67. Zhu, B. et al. Direct asymmetric vinylogous aldol reaction of allyl ketones with isatins: divergent synthesis of 3-hydroxy-2-oxindole derivatives. Angew. Chem. Int. Ed. 52, 6666-6670 (2013).

68. Zhan, G., He, Q., Yuan, X. \& Chen, Y.-C. Asymmetric direct vinylogous Michael additions of allyl alkyl ketones to maleimides through dienamine catalysis. Org. Lett. 16, 6000-6003 (2014).

69. Shi, M.-L., Zhan, G., Zhou, S.-L., Du, W. \& Chen, Y.-C. Asymmetric inverseelectron-demand oxa-Diels-Alder reaction of allylic ketones through dienamine catalysis. Org. Lett. 18, 6480-6483 (2016).

70. Zhang, L., Fu, N. \& Luo, S. Pushing the limits of aminocatalysis: enantioselective transformations of $\alpha$-branched $\beta$-ketocarbonyls and vinyl ketones by chiral primary amines. Acc. Chem. Res. 48, 986-997 (2015).

\section{Acknowledgements}

We are grateful to the National Science Foundation of China (No. 21822103, 21820102003, 21772052, 21772053 and 21572074), the Program of Introducing Talents of Discipline to Universities of China (111 Program, B17019), the Natural Science Foundation of Hubei Province (2017AHB047) and International Joint Research Center for Intelligent Biosensing Technology and Health for support of this research. Prof. Dr. Sanzhong Luo in Institute of Chemistry (CAS, Beijing) is sincerely acknowledged for helpful discussion about the enantio- and diastereodivergent cycloaddition of aminoalcohols with $\beta, \gamma$-unsaturated ketones and for providing their chiral primary amine catalysts.

\section{Author contributions}

L.-Q.L. and W.-J.X. supervised the project. M.-M.Z., Y.-N.W., B.-C.W., and X.-W.C. performed the experiments. L.-Q.L. and W.-J.X. wrote the manuscript, and all the authors contributed to the discussion.

\section{Additional information}

Supplementary Information accompanies this paper at https://doi.org/10.1038/s41467 019-10674-3.

Competing interests: The authors declare no competing interests.

Reprints and permission information is available online at http://npg.nature.com/ reprintsandpermissions/

Peer review information: Nature Communications thanks the anonymous reviewer(s) for their contribution to the peer review of this work.

Publisher's note: Springer Nature remains neutral with regard to jurisdictional claims in published maps and institutional affiliations.

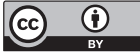

Open Access This article is licensed under a Creative Commons Attribution 4.0 International License, which permits use, sharing, adaptation, distribution and reproduction in any medium or format, as long as you give appropriate credit to the original author(s) and the source, provide a link to the Creative Commons license, and indicate if changes were made. The images or other third party material in this article are included in the article's Creative Commons license, unless indicated otherwise in a credit line to the material. If material is not included in the article's Creative Commons license and your intended use is not permitted by statutory regulation or exceeds the permitted use, you will need to obtain permission directly from the copyright holder. To view a copy of this license, visit http://creativecommons.org/ licenses/by/4.0/.

(C) The Author(s) 2019 